\title{
Metodologias ativas no processo de ensino e de aprendizagem: Alternativas didáticas emergentes
}

\author{
Active methodologies in the teaching and learning process: Emerging didactic alternatives \\ Metodologías activas en el proceso de enseñanza y aprendizaje: Alternativas didácticas emergentes
}

Recebido: 20/03/2021 | Revisado: 30/03/2021 | Aceito: 04/04/2021 | Publicado: 14/04/2021

\author{
Marcos Adriano Barbosa de Novaes \\ ORCID: https://orcid.org/0000-0002-5003-5418 \\ Faculdade de Filosofia Dom Aureliano Matos, Brasil \\ E-mail: marcos.educare@ hotmail.com \\ Everton Sousa da Silva \\ ORCID: https://orcid.org/0000-0001-6786-8187 \\ Faculdade de Filosofia Dom Aureliano Matos, Brasil \\ E-mail: evertons.silva@aluno.uece.br \\ Maira Kelly Rodrigues Costa \\ ORCID: https://orcid.org/0000-0003-0702-3152 \\ Faculdade de Filosofia Dom Aureliano Matos, Brasil \\ E-mail: maira.kelly@aluno.uece.br \\ Priscila Azevedo de Amorim \\ ORCID: https://orcid.org/0000-0002-9521-5279 \\ Faculdade de Educação de Itapipoca, Brasil \\ E-mail: priscilaazevedo233@gmail.com \\ Frank Lane Macedo Machado \\ ORCID: https://orcid.org/0000-0002-6125-9361 \\ Secretaria de Educação do Ceará, Brasil \\ E-mail: franklanehott@gmail.com \\ Ana Moésia Magalhães Ribeiro Machado \\ ORCID: https://orcid.org/0000-0003-4010-7657 \\ Universidade Regional do Cariri, Brasil \\ E-mail: moesia-mv@hotmail.com \\ Johnantan Santiago Moura \\ ORCID: https://orcid.org/0000-0002-4445-4755 \\ Escola de Educação Básica Colégio Diocesano Padre Anchieta, Brasil \\ E-mail: sjohnantan@yahoo.com.br \\ Cícero Ricardo Barbosa de Paiva \\ ORCID: https://orcid.org/0000-0002-1554-9552 \\ Universidade Estadual Vale do Acaraú, Brasil \\ E-mail: prof.ricardopaivace@gmail.com \\ Iara Saraiva Martins \\ ORCID: https://orcid.org/0000-0002-5235-7461 \\ Instituto Federal de Educação, Ciência e Tecnologia do Ceará, Brasil \\ E-mail: saraiva.iara@ifce.edu.br \\ Francisco Glauber de Oliveira Paulino \\ ORCID: https://orcid.org/0000-0001-5312-569X \\ Universidade Estadual do Ceará, Brasil \\ E-mail: francisco.paulino@aluno.uece.br \\ Maria Núbia de Araújo \\ ORCID: https://orcid.org/0000-0002-6386-8021 \\ Universidade Estadual do Ceará, Brasil \\ E-mail: nubia.araujo@aluno.uece.br \\ Jarles Lopes de Medeiros \\ ORCID: https://orcid.org/0000-0003-0942-6764 \\ Universidade Estadual do Ceará, Brasil \\ E-mail: jarleslopes@yahoo.com.br \\ Amélia Soares André \\ ORCID: https://orcid.org/0000-0002-9189-9968 \\ Universidade Estadual Vale do Acaraú, Brasil \\ E-mail: amelimel@yahoo.com.br
}

\section{Resumo}

As Metodologias Ativas (MA’s), surgidas nas últimas décadas do século XX, podem ser compreendidas como um conjunto de métodos que buscam desenvolver a autonomia dos alunos no processo de aquisição do conhecimento. Pensando nisso, através do aporte teórico de autores como Moran (2015), Bacich (2015), Masetto (2010), Dewey 
(2010) e Freire (2009), apresentamos as MA's como nosso objeto de estudo. Para isso, mediante à natureza revisional do método utilizado, recorremos à pesquisa descritiva, com abordagem qualitativa. Por sua vez, essas bases conceitual e metodológica nos levaram às seguintes problemáticas: O que são MA's e em quais tipos se categorizam? Quais as características do ensino ativo? E, por fim, quais as contribuições delas na aprendizagem do aluno? Partindo destas questões, esse artigo objetiva, em um primeiro momento, apresentar alguns tipos de MA's e, em um segundo momento, as atividades realizadas no ano de 2020 na oficina "Metodologias ativas: aprendizagem através de rotação por estações, laboratório rotacional e sala de aula invertida", vinculada ao Projeto de Extensão "Metodologias Ativas no processo de ensino e aprendizagem na E.E.F. Maria Gonçalves da Rocha Leal em Limoeiro do Norte-CE" pelo Curso de Pedagogia da Faculdade de Filosofia Dom Aureliano Matos (FAFIDAM/UECE). Segundo nossas análises preliminares, a utilização de MA's configura-se como uma ferramenta auxiliar no processo de ensino e de aprendizagem. Por isso, é importante enfatizar que nenhuma metodologia deve ser responsabilizada, isoladamente, pelo sucesso ou fracasso do alunado, visto que há inúmeras adversidades que permeiam o contexto educacional brasileiro, sobretudo nas escolas públicas.

Palavras-chave: Metodologias ativas; Estratégias de ensino; Ensino híbrido.

\begin{abstract}
Active Methodologies (AM's), which emerged in the last decades of the twentieth century, can be understood as a set of methods that seek to develop the autonomy of students in the process of acquiring knowledge. Thinking about it, through the theoretical contribution of authors such as Moran (2015), Bacich (2015), Masetto (2010), Dewey (2010) and Freire (2009), we present AM's as our object of study. For this, due to the revisionary nature of the method used, we resorted to descriptive research, with a qualitative approach. In turn, these conceptual and methodological bases have led us to the following problems: What are AM's and in which types are they categorized? What are the characteristics of the active study? And, finally, what are their contributions to student learning? Starting from these questions, this article aims, in a first moment, to present some types of AM's and, in a second moment, the activities carried out in the year 2020 in the workshop "Active methodologies: learning through rotation by seasons, rotational laboratory, and inverted classroom", linked to the Extension Project " Active Methodologies in the teaching and learning process at the Elementary School Maria Gonçalves da Rocha Leal in Limoeiro do Norte-CE " by the Pedagogy Course of the College of Philosophy Dom Aureliano Matos (FAFIDAM / UECE). According to our preliminary analyzes, the use of AM's is configured as an auxiliary tool in the teaching-learning process. For this reason, it is important to emphasize that no methodology should be held responsible, in isolation, for the success or failure of the students, since there are numerous adversities that permeate the Brazilian educational context, especially in public schools.
\end{abstract}

Keywords: Active methodologies; Teaching strategies; Hybrid teaching.

\title{
Resumen
}

Las Metodologías Activas (MA's), surgidas en las últimas décadas del siglo XX, pueden entenderse como un conjunto de métodos que buscan desarrollar la autonomía de los alumnos en el proceso de adquisición de conocimientos. Con esto en mente, a través del aporte teórico de autores como Moran (2015), Bacich (2015), Masetto (2010), Dewey (2010) y Freire (2009), presentamos a los AM como nuestro objeto de estudio. Para ello, debido al carácter revisable del método utilizado, se recurrió a una investigación descriptiva con un enfoque cualitativo. A su vez, estas bases conceptuales y metodológicas nos llevaron a los siguientes problemas: ¿Qué son las AM y en qué tipos se clasifican? ¿Cuáles son las características del estudio activo? Y, por último, ¿cuál es su contribución al aprendizaje de los alumnos? A partir de estas cuestiones, este artículo pretende, en un primer momento, presentar algunos tipos de MA's y, en un segundo momento, las actividades realizadas en 2020 en el taller "Metodologías activas: aprendizaje a través de la rotación por estaciones, laboratorio rotativo y aula invertida", vinculado al Proyecto de Extensión "Metodologías activas en el proceso de enseñanza y aprendizaje en la E.E.F. Maria Gonçalves da Rocha Leal en Limoeiro do NorteCE" por el Curso de Pedagogía de la Facultad de Filosofía Dom Aureliano Matos (FAFIDAM/UECE). Según nuestros análisis preliminares, el uso de los MA's se configura como una herramienta auxiliar en el proceso de enseñanza-aprendizaje. Por lo tanto, es importante destacar que ninguna metodología debe ser considerada responsable, de forma aislada, del éxito o del fracaso de los alumnos, ya que existen numerosas adversidades que impregnan el contexto educativo brasileño, especialmente en las escuelas públicas.

Palabras clave: Metodologías ativas; Estrategias de enseñanza; Enseñanza híbrida.

\section{Introdução}

Existe uma intensa utilização social das mídias e Tecnologias Digitais de Informação e Comunicação (TDIC). Portanto, é correto afirmar que vivemos em um espaço híbrido multimodal da hiperconexão, que influencia nossa vida, nosso modo de pensar, agir, interagir e se expressar. De forma semelhante, também acrescenta novos elementos à nossa aprendizagem. E estes, por sua vez, podem proporcionar contribuições positivas; mas, também desafios ao processo educativo. 
Todavia, esses obstáculos nos fazem repensar sobre novas propostas educativas que superem o método tradicional, fazendo com que o aluno supere a passividade e passe a ser sujeito ativo nos processos de ensino e aprendizagens.

Atualmente, essa transformação se faz possível, sobretudo, porque

as tecnologias ampliam as possibilidades de pesquisa online, de trazer materiais importantes e atualizados para o grupo, de comunicar-nos [sic] com outros professores, alunos e pessoas interessantes, de ser coautores, "remixadores" de conteúdos e de difundir nossos projetos e atividades, individuais, grupais e institucionais muito além das fronteiras físicas do prédio. (Moran, 2015, p. 19)

Dito de outra maneira, a cultura digital já é parte da sociedade e trouxe, doravante, grandes mudanças em praticamente todos os segmentos sociais. Na educação, as características e práticas sociais dessa nova realidade implicam a necessidade de mudanças no fazer docente, anteriormente pautado, de forma restrita, na memorização e repetição de informações, sem considerar a individualidade do aluno.

Contudo, tais procedimentos não fazem mais sentido no atual contexto de contínuo desenvolvimento tecnológico porque, com a personalização do ensino, as tecnologias ampliaram o acesso dos alunos a recursos ativos, como games e videoaulas. No mais, esses recursos possibilitam ainda que o educando identifique as estratégias mais eficientes para o próprio aprendizado, das mais diversas áreas do conhecimento. Para isso, este público, predominantemente jovem, utiliza-se de ferramentas digitais cada vez mais variadas e dinâmicas, que ajudam a entender a aplicabilidade dos conhecimentos adquiridos.

Com a utilização de métodos de ensino ativos, passa-se a olhar mais para o processo, buscando identificar de que maneira o discente está trabalhando para construir os seus conhecimentos auxiliados pelo uso das tecnologias. Consequentemente, as novas tecnologias têm impacto sobre o currículo escolar, podendo auxiliar os docentes no desenvolvimento de metodologias que colocam o aluno no centro do processo educativo, permitindo ainda que o educador possa conceituar e compreender os métodos e aprendizagens ativas.

Assim, com a utilização das TDICs, o processo educativo torna-se mais dinâmico, rompendo as práticas pedagógicas que se estabeleceram, ao longo de séculos. Diante disso, o ensino híbrido busca a personalização da tecnologia na educação, novas formas de aprender e de ensinar: possibilidades que ampliam e potencializam a aprendizagem do aluno.

No que se pese a essa personalização, há inevitáveis modificações nos processos de ensino e de aprendizagem, devido à implementação das tecnologias digitais no âmbito educacional, uma vez que será levado em conta aspectos como tempo, ritmo, lugar, assim como a forma de aprendizagem do discente. Com isso,

As modificações possibilitadas pelas tecnologias digitais querem novas metodologias de ensino, as quais necessitam de novos suportes pedagógicos, transformando o papel do professor e dos estudantes e ressignificando o conceito de ensino e aprendizagem. Nesse sentido, o ensino on-line permite que tal personalização, uma vez que pode ajudar a preencher lacunas no processo de aprendizagem. (Bacich; Tanzi Neto; Trevisani, 2015, p. 51)

Nesse sentido, a hibridização do ensino facilita para que o educador obtenha informações individuais sobre os alunos. Essas informações permitem o uso de recursos que auxiliam no desenvolvimento de novas estratégias, de acordo com as necessidades de cada um, proporcionando a personalização do ensino alinhado com o uso da tecnologia. Um ensino nestes moldes traz uma mistura entre o ensino presencial e on-line, dividido em quatro modelos, conforme Christensen et al (2013): 1. o "Modelo Rotacional", que possui quatro subdivisões: 1.1 "Rotação por estação"; 1.2 "Laboratório rotacional"; 1.3 "Sala de aula invertida"; 1.4 "Rotação individual"; 2. "Modelo Flex"; 3. "Modelo à la carte"; e 4. "Modelo virtual enriquecido". Cada um destes com abordagens, características e definições próprias, que serão detalhados no tópico 3.

Além do mais, as MA's proporcionam curiosidade aos alunos pois, à medida em que eles se incluem nos processos de ensino e de aprendizagens, apresentam novos elementos que não foram analisados na aula tradicional. Partindo dessas ideias 
iniciais, fomentadas por nosso aporte teórico de autores como Moran (2015), Bacich (2015), Masetto (2010), Dewey (2010) e Freire (2009), apresentamos as MA's como nosso objeto de estudo. Para isso, mediante à natureza revisional do método utilizado, recorremos à pesquisa descritiva, com abordagem qualitativa. Conquanto, a vivência profissional docente e formação acadêmica alicerçada pela bibliografia consultada nos impulsiona aos seguintes questionamentos: O que são MA's e em quais tipos se categorizam? Quais as características do estudo ativo? E, por fim, quais as contribuições delas na aprendizagem do aluno?

Neste sentido, este estudo é resultado das leituras realizadas no Projeto" de Extensão "Metodologias Ativas no processo de ensino e aprendizagem na Escola E.E.F. Maria Gonçalves da Rocha Leal", realizado pelo curso de Pedagogia na Faculdade de Filosofia Dom Aureliano Matos (FAFIDAM) da Universidade Estadual do Ceará (UECE), campus Limoeiro do Norte - Ceará. Neste viés, esse artigo objetiva, primeiramente, apresentar alguns tipos de MA's e, em um segundo momento, as atividades realizadas no ano de 2020 na oficina "Metodologias ativas: aprendizagem através de rotação por estações, laboratório rotacional e sala de aula invertida", vinculada ao supracitado projeto de extensão. Por fim, nossas conclusões preliminares nos possibilitaram compreender as contribuições das MA's, importantes ferramentas no processo de ensino aprendizagem, que buscam a interação entre os professores e alunos, gerando uma troca de experiências. Com isso, as TIDIC's, que servem de base para essas metodologias, possuem como característica basilar a agilidade na comunicação e no compartilhamento de informações, o que pode facilitar o processo de aquisição do conhecimento.

\section{Metodologias Ativas: Possibilidade na Sala de Aula}

As primeiras práticas de ensino que colocam o aluno na condição ativa de aprendizagem datam de, aproximadamente, meados do século V A.C, dentro da filosofia socrática, que se caracterizava pela indagação contínua do discípulo. Esta concepção influenciou estudiosos como Freire, Dewey e Vygotsky na defesa da participação ativa do educando no processo de ensino. Todavia, só muito tempo depois, em 1980, surgem as Metodologias Ativas (MA’s). Estas apresentam como principal objetivo de ensino o incentivo ao educando para o desenvolvimento da capacidade de compreensão dos conteúdos, de forma autônoma e participante dos educandos. Segundo Bastos (2006):

[...] as metodologias ativas são processos interativos de conhecimento, análise, estudos, pesquisas e decisões individuais ou coletivas, com a finalidade de encontrar soluções para um problema. É o processo de ensino em que a aprendizagem depende também do aluno, que sai da posição de mero receptor. (Bastos, 2006 apud Peixoto, 2016, p. 39)

Sendo assim, as metodologias ativas têm por finalidade a aprendizagem autônoma do alunado, estimulando o protagonismo do estudante para assumirem a responsabilidade de seu processo de aprender. Nesse sentido, estudiosos, como Dewey $(2010)^{2}$ e outros, defendem a participação ativa do aluno durante o processo de ensino, sendo necessário, para isso, envolve-los em atividades cada vez mais complexas, tornando-os criativos e atuantes na tentativa se superar a concepção

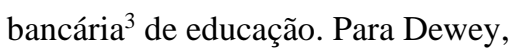

A atividade educativa não se processa no vácuo, independente de objeto ou condições. Ao contrário, ela é sempre uma resposta a estímulos específicos ou gerais, nascidos do próprio organismo e do meio ambiente em que o indivíduo vive. (Dewey, 2010, p. 42).

\footnotetext{
${ }^{1}$ Devido a Pandemia da COVID-19 não foi possível realizar o Projeto de Extensão na escola parceira.

2 Dewey (1959) defende uma educação que crie, no aluno, valores sociais, humanitários e aspectos culturais a terem a devida importância reconhecida, mediante ao ambiente onde este indivíduo está inserido. Da mesma forma, Freire (2009) aborda a defesa de um ensino mais ativo e participativo na composição de cada ser, cuja centralidade do ensino seja o compartilhamento de ideias entre professor e aluno.

${ }^{3}$ Ver Freire (2014), capítulo 2: A concepção Bancária da educação como instrumento da opressão. Seus pressupostos, sua crítica.
} 
Dito isso, as MA's em sala de aula buscam estimular o indivíduo a ser mais crítico e atuante dentro de um processo autônomo de aprendizagem. Dessa forma, os discentes passariam a refletir sobre as possibilidades de resolução dessas questões objetivas das atividades ou avaliações escolares, através de ensaios com erros e acertos, o que na visão de Coletto; Battini e Monteiro (2018) proporciona um novo rumo ao que diz respeito ao ensino educacional atual, pois mobilizam os educandos a possuírem uma melhor aquisição de conhecimento durante sua formação tanto pessoal como profissional onde ele estiver inserido. Cabe, pois, aos professores mediarem as questões surgidas através dos questionamentos, bem como reflexões sobre acertos e erros. Com a utilização destes métodos, podemos inverter a forma de ensino, buscando identificar o que e como o aluno pode aprender. Isso o permite construir a autonomia do discente, já que:

Os docentes deixam de ser os principais depositários do conhecimento e passam a ser consultores metodológicos e animadores de grupos de trabalho. Esta estratégia obriga a reformular os objetivos da educação. O desenvolvimento de competências-chave [...] substitui a sólida formação disciplinar até então visada. (Labarca, 1995 apud Barreto, 2004, p. 14)

Sendo assim, as MA's expressam novas formas de ensino, por meio de um conjunto de técnicas que possibilitam o aluno desenvolver, nas suas atividades, o aprender fazendo, sem desconsiderar a reflexão do significado daquilo que o estudante construiu. Portanto, as MA's são estratégias de ensino desenvolvidas com foco na participação efetiva do aluno em seu processo educacional, de modo flexível, interligado e híbrido. Todavia,

O estudo ativo requer planejamento, organização e controle, de modo que acompanhem todos os momentos ou passos da aula [...] se converta numa necessidade para o aluno e que seja um estímulo suficiente para canalizar a sua necessidade de atividade. Trata-se da conjugação de condições internas dos alunos e de condições externas expressas pelas exigências e expectativas e incentivos de professor. (Libâneo, 2013.p. 108)

Dessa forma, as MA'S apresentam alternativas que podem complementar o ensino tradicional, com métodos que tornem o aluno um ser ativo, com uma maior capacidade crítica, evidenciando sempre a autonomia dos alunos em seus processos de ensino e de aprendizagens.

Neste sentido, as MA's levam em consideração tanto as experiências vivenciadas sem o uso das novas tecnologias quanto as virtuais. Assim, possibilita-se que o discente aguce a capacidade dele em solucionar os desafios proporcionados pela prática social, em distintos contextos, contribuindo na construção de um ser crítico, reflexivo, ético e ativo. Consequentemente, desloca-se o aluno ao centro do processo de ensino e aprendizagem, princípio defendido pelos adeptos do movimento escolanovista. Nessa concepção de ensino, há o predomínio dos “[...] pressupostos psicológicos, psicopedagógicos e experimentais, cientificamente validados na experiência e constituídos em teoria [...]" (Veiga, 2012, p. 38). Desta forma,

[...] os métodos de ensino são considerados em estreita relação com os métodos de aprendizagem (ou métodos de assimilação ativa); ou seja, os métodos de ensino fazem parte do papel de direção do processo de ensino por parte do professor tendo em vista a aprendizagem dos alunos. (Libâneo, 2013. p. 160)

Em síntese, elas se desdobram em vários modelos de métodos ativos combinados com o ensino híbrido, que se divide em: 1. Modelo Rotacional (subdivide-se em Rotação por estação, Laboratório rotacional, Sala de aula invertida e Rotação individual); 2. Modelo Flex; 3 . Modelo à la carte; e 4. Modelo virtual enriquecido.

O modelo rotacional consiste na ação de rotacionar o tema da aula, ou seja, os educandos alternam entre os métodos de aprendizado on-line, respeitando o ritmo de cada um deles, facilitando a aprendizagem. Este modelo utiliza ainda alguns elementos da aula tradicional, como a exposição do conteúdo. Dentro desta metodologia, desdobra-se o Laboratório Rotacional, que utiliza a tecnologia para aumentar a eficiência operacional dos educandos. Todavia, é importante que se alerte que este modelo facilita o aprendizado personalizado; mas, não substitui as atividades tradicionais em sala de aula. 
A sala de aula invertida, por sua vez, consiste em inverter a aula expositiva: as informações são direcionadas aos alunos em formatos digitais como vídeos e textos, para que eles saibam previamente sobre o que irão conversar e discutir em sala. No que se refere ao modelo de rotação por estações, o aluno é direcionado a áreas distintas do conhecimento. Para isso, os discentes são divididos em grupos que refletem sobre pontos de vista dentro de uma mesma temática de aula. Na sequência, compartilham o conteúdo proposto para que, assim, possibilitem um conhecimento amplo, auxiliados pela criatividade, pesquisa e o meio tecnológico.

Por sua vez, no Modelo Flex, os educandos possuem uma lista de temas a serem estudados através de ferramentas online. Assim sendo, pode-se inferir que o ritmo de cada aluno deverá ser personalização e acompanhado pelo docente, que deverá ficar suprir as dúvidas. Contudo, esse modelo é considerado como disruptivo, propondo uma organização de escola que ainda é considera incomum no Brasil. No modelo à la carte, o educando deve ser responsável pela própria estruturação de seus estudos, seguindo uma linha ou guia de objetivos gerais a serem cumpridos, podendo necessitar do auxílio do docente. Desta forma, a aprendizagem, em local e momento adequados, apresentará também caráter personalizado, sendo ofertado um curso on-line. Por fim, o modelo virtual enriquecido apresenta duas divisões do tempo: um em aprendizagem presencial e outro, online. Dessa forma, esse modelo permite que o educando se apresente, em um espaço físico, uma vez na semana. Logo, é caracterizado como disruptivo pois propõe uma estruturação escolar basilar, sendo incomum no Brasil.

Mediante a todos esses modelos apresentados, podemos refletir sobre o quanto a inserção das MA's no processo de ensino e aprendizagem possibilita trocas de experiências, resultados produtivos e a realização de pesquisas. Corroborando com essa ideia, Moran (2013) enfatiza que:

[...] Se queremos que os alunos sejam proativos, precisamos adotar metodologias em que os alunos se envolvam em atividades cada vez mais complexas, em que tenham que tomar decisões e avaliar os resultados, com apoio de materiais relevantes. Se queremos que sejam criativos, eles precisam experimentar inúmeras novas possibilidades de mostrar sua iniciativa. (Moran, 2013, p. 01)

Sendo assim, o professor tem como função desenvolver estímulos na autoaprendizagem e nas curiosidades discentes, para que o aluno pesquise, reflita e analise o conhecimento adquirido. Nesse sentido, o educador assume a função de facilitador do processo de aprendizagem ativa, na tentativa de engajar os estudantes em atividades reflexivas, uma vez que as MA's possuem ligação com a prática, com projetos, com jogos e com o cotidiano. O professor, por sua vez, seleciona as informações e conduz os alunos na perspectiva de que "a melhor forma de aprender é combinando equilibradamente atividades, desafios e informação contextualizada. As metodologias precisam acompanhar os objetivos pretendidos”. (Morán, 2015, p.17).

Com o uso das MA's, há um maior envolvimento dos alunos no processo de ensino e aprendizagem, pois eles são estimulados a pesquisar antes do conteúdo ser exposto, levando para sala de aula um conhecimento prévio, facilitando o desenvolvimento de atividades mais avançadas em classe. Outrossim, o professor recorre ao aprofundamento do conteúdo, promovendo o diálogo e o debate.

De acordo com Gaeta e Masetto (2010), a relevância dessas metodologias só possuem validade quando estão envolvidas diretamente aos objetivos da aprendizagem; do contrário, não serão alcançados os resultados esperados. Sendo assim, faz-se necessário que o professor tenha um planejamento que explicite os seus objetivos de aprendizagem e diversifique os métodos e estratégias de ensino que contribuam com o desenvolvimento dos alunos. Por fim, as MA's tencionam uma educação que possibilite aos alunos a construção consciente de suas trilhas de aprendizagem, valores e competências. Assim, tais metodologias evidenciam a necessidade de trabalhos em grupos, projetos, problemas e, sobretudo, inversão dos sujeitos no processo de busca constante de uma aprendizagem prazerosa e significativa. 


\section{O Caminho Trilhado...}

Este artigo parte, em um primeiro momento, de uma pesquisa de revisão bibliográfica narrativa ${ }^{4}$, que possui como fito básico a fundamentação teórica do tema aqui abordado. Somado a isso, considerando a natureza do objetivo desse estudo, recorremos à pesquisa metodológica, de método dedutivo, por meio da abordagem descritiva (PRESTES, 2013), cujos dados foram analisados de forma qualitativa, já que, para compreender melhor o nosso objeto de estudo, não pretendemos mensurar ou quantificar valores, e sim analisar, de forma crítica, a temática em questão.

Somado a isso, realizamos, em 2020, a oficina "Metodologias ativas: aprendizagem através de rotação por estações, laboratório rotacional e sala de aula invertida", atividade desenvolvida pelo Projeto de Extensão "Metodologias Ativas no processo de ensino e aprendizagem na Escola E.E.F. Maria Gonçalves da Rocha Leal em Limoeiro do Norte-CE”, através do Curso de Pedagogia da Faculdade de Filosofia Dom Aureliano Matos (FAFIDAM) da Universidade Estadual do Ceará (UECE), campus Limoeiro do Norte. Sendo assim, buscamos, com o conhecimento produzido nesta oficina, apresentar à comunidade acadêmica como as MA's estimulam as diferentes formas de aprendizagem dos alunos, tornando as aulas mais dinâmicas. Para isso, é necessário que os professores e os aspirantes à docência conheçam e dominem novos métodos que possam contribuir para uma aprendizagem mais significativa e prazerosa, rompendo com o modelo tradicional de ensino.

Ressaltamos que as MA's são alinhadas ao Ensino Híbrido, que busca a personalização da tecnologia na educação e novas formas de aprender e ensinar, o que amplia e potencializa a aprendizagem do aluno. Dessa forma, essa personalização se caracteriza com modificações no processo de ensino-aprendizagem, devido à implementação das tecnologias digitais no âmbito educacional, considerando o tempo, ritmo, espaço de cada aluno.

Além disso, a hibridização do ensino traz uma mistura entre o ensino presencial e on-line, dividido em quatro modelos, já apresentados no tópico anterior; dentre outros, como a Gamificação e a Aprendizagem Baseada em Problemas (PBL). Por fim, trabalhamos, na oficina, os modelos de Rotação por Estações, Laboratório Rotacional e Sala de Aula Invertida, na tentativa de contribuir com práticas docentes inovadoras.

A oficina foi realizada no período de 19 a 21 de outubro de 2020. Porém, devido ao contexto da pandemia do COVID19, a atividade foi realizada virtualmente, via Google Meet, pelos bolsistas do referido projeto de extensão, sob a coordenação do professor orientador. Neste viés, a ação teve como objetivo conceituar e categorizar as Metodologias Ativas; bem como buscou-se refletir sobre as contribuições dessas dentro e fora da sala de aula, utilizando os modelos: rotação por estações, laboratório rotacional e sala de aula invertida na elaboração dos Planos de Aula. Para isso, fizemos uso da aula expositiva e dialogada, assim como propomos exercícios práticos de elaboração de plano de aula, utilizando duas das três metodologias apresentadas na oficina.

No que se pese ao conteúdo programático da atividade, foram destinadas 12 horas para estudos teóricos, contemplando os seguintes conteúdos: a) Didática: breves apontamentos; b) Conceito e características das Metodologias Ativas; c) Tipos de Metodologias Ativas; d) A importância do Plano de Aula no processo de ensino e aprendizagem; e e) Plano de aula utilizando Metodologias Ativas. Já em relação à parte prática da oficina, tivemos 8 (oito) horas divididas na elaboração do Plano de aula utilizando duas das três metodologias do curso: Rotação por Estações, Laboratório Rotacional e Sala de Aula Invertida.

\section{Conhecendo e Identificando metodologias Emergentes de Ensino}

A oficina, ao apresentar e conceituar as metodologias ativas, possibilitou aos estudantes participantes refletir sobre a importância da atuação dos alunos da escola básica, de maneira ativa na construção do conhecimento. Somado a isso, os

\footnotetext{
${ }^{4}$ Para maiores informações sobre este método, consulte o material disponibilizado pela Biblioteca Prof. Paulo de Carvalho Matos da Faculdade de Ciências Agronômicas da UNESP - Campus de Botucatu. Disponível em <https://www.fca.unesp.br/Home/Biblioteca/tipos-de-evisao-de-literatura> Acesso em 12 de março de 2021.
} 
participantes pareceram compreender a relevância da inserção desses métodos na escola, o que nos leva a acreditar que a identificação das distintas formas de ministrar a aula também podem proporcionar reflexões críticas, dinamizando todo o processo de aprendizagem. Todavia, é importante ter em mente que:

a questão não é introduzir na escola as várias mídias, as linguagens e os textos que emergem do digital. É preciso, acima de tudo, criar condições para formas de leitura plurais e para concepções de ensino e aprendizagem que considerem o aprendiz como protagonista, a fim de diminuir a distância entre as leituras e as práticas que se desenvolvem fora da escola e aquelas que são privilegiadas por ela. (Barreto, 2011, p. 67).

$\mathrm{Na}$ verdade, com vista a colocar o aluno como sujeito ativo, engajado no percurso da construção do saber, o Ensino Híbrido apresenta-se como uma alternativa, que se apoia na mesclagem entre atividades off-line e situações mediadas pela tecnologia, uma vez que

Híbrido significa misturado, mesclado, blended [...] A educação é híbrida também porque acontece no contexto de uma sociedade imperfeita, contraditória em suas políticas e em seus modelos, entre os ideais afirmados e as práticas efetuadas; muitas das competências socioemocionais e valores apregoados não são coerentes com o comportamento cotidiano de uma parte dos gestores, docentes, alunos e famílias [...] (Moran, 2015, p.27).

$\mathrm{Na}$ oficina, apresentamos o modelo rotacional, cuja principal característica é desenvolver diferentes ambientes em sala de aula. Para isso, é formado um circuito para uma melhor abordagem do conteúdo, que é apresentado por meio de dois ambientes: on-line e off-line. Desta maneira, busca-se estimular os alunos a diferentes formas de aprendizagem. No entanto, diante do contexto da pandemia da COVID-19, exige-se um número reduzido de alunos.

Figura 1 - Laboratório Rotacional.

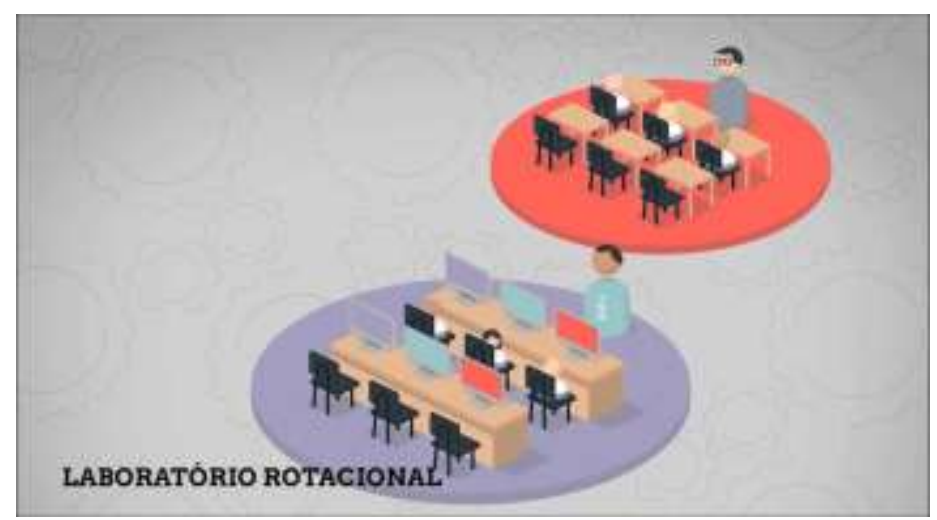

Fonte: https://cutt.ly/xf8Fofm.

Nessa perspectiva, outro modelo inovador é a sala de aula invertida, que traz uma proposta inversa ao ensino tradicional. Neste modelo, o aluno é orientado a estudar o conteúdo antecipadamente, para que durante a aula, o professor consiga se aprofundar no conteúdo. Contudo, cada aluno aprende no seu ritmo, antes mesmo de a aula iniciar. Nesse modelo, os participantes da oficina, em diversos momentos, afirmaram na sala do Google Meet que é necessário romper centralidade do professor no processo de ensino e aprendizagem. Para isso, temos que desenvolver, desde cedo, em nossos alunos a autonomia e a responsabilidade. No entanto, isso só será possível se a aula for dinâmica, divertida e sem imposição autoritária da escola e do professor. É necessário nos prepararmos para os alunos que já nasceram inseridos no contexto de um auto desenvolvimento tecnológico. 
Figura 2 - Sala de aula invertida.

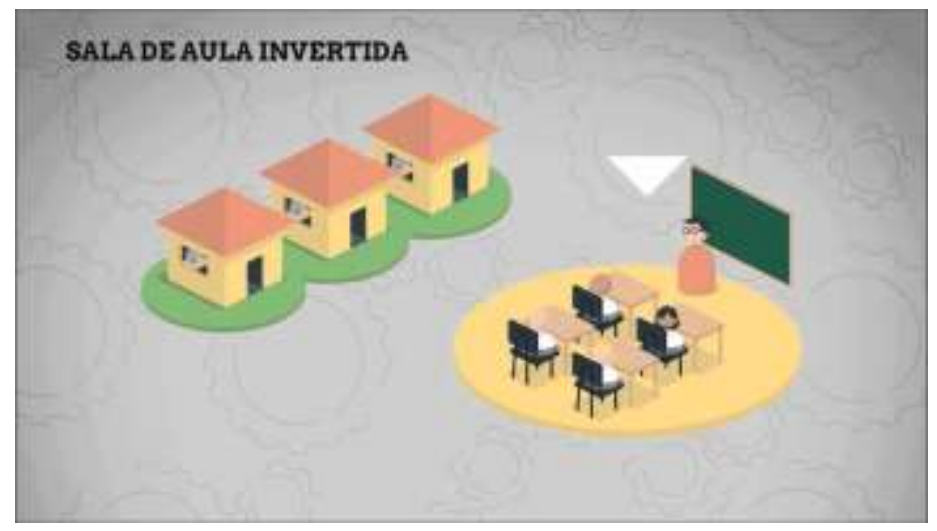

Fonte: https://cutt.ly/ff8FbzO

Já, o modelo Rotação por estações é desenvolvido por meio de circuitos, que proporcionam ao discente aprender o conteúdo de diversas formas. Confira as imagens a seguir:

Figura 3 - Rotação por estações.

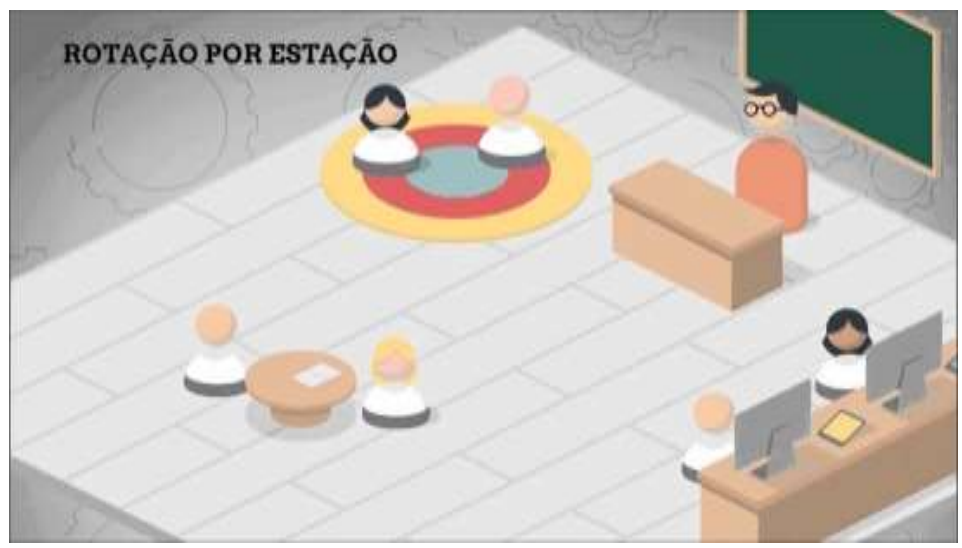

Fonte: https://cutt.ly/Of8F3Gc.

Não obstante, as metodologias necessitam estar alinhadas aos objetivos educacionais almejados; ou seja, para o desenvolvimento das competências como criatividade, o pensamento crítico e a argumentação, é fundamental que as situações didáticas definidas pela comunidade escolar sejam formuladas considerando esses elementos. Portanto,

As metodologias precisam acompanhar os objetivos pretendidos. Se queremos que os alunos sejam proativos, precisamos adotar metodologias em que os alunos se envolvam em atividades cada vez mais complexas, em que tenham que tomar decisões e avaliar os resultados, com apoio de materiais relevantes. Se queremos que sejam criativos, eles precisam experimentar inúmeras novas possibilidades de mostrar sua iniciativa (Moran, 2020, p.1).

Ademais, durante o processo de ensino, deve-se sempre considerar a participação ativa do aluno. Logo, é necessário que ele esteja engajado nas propostas. Para isso, muitas das metodologias ativas usam questões norteadoras ou situações problemas como ponto de partida. Nesse sentido, os participantes puderam perceber, através de exemplos expostos nos momentos da oficina, que as MA's permitem diversificar as propostas, considerando a heterogeneidade da turma. 


\section{Considerações Finais}

Em síntese, percebemos que a utilização de MA's é uma possibilidade que pode ajudar no processo de ensino e aprendizagem. Entretanto, chamamos a atenção para o fato de que nenhuma metodologia deve ser responsabilizada pelo sucesso ou fracasso da aprendizagem escolar, pois há adversidades que permeiam o sistema educacional brasileiro, sobretudo nas escolas públicas.

Nesse sentido, as Metodologias Ativas buscam desenvolver uma postura mais ativa dos nossos alunos em sala de aula. Esta prática pedagógica busca aumentar a comunicação, colaboração e compartilhamento, criatividade e pensamento crítico, para isso, podemos recorrer ao Ensino Híbrido e seus quatro modelos: rotacional (Laboratório Rotacional; Sala de aula invertida; Rotação por estações e Rotação individual); Modelo Flex, Modelo A la Carte e Modelo virtual enriquecido.

Portanto, as MA's são recursos de aprimoramento do processo didático. Assim, provêm o trabalho coletivo e a construção de indivíduos participativos, críticos e reflexivos.

Compreendemos, neste sentido, que o ensino ativo busca desenvolver uma relação horizontal, através da interação e troca de conhecimento entre professor e aluno.

Por fim, os desafios para essa educação inovadora no ensino devem ir além das barreiras impostas, propondo assim que as instituições de ensino sejam capazes de inovar na educação com o uso das novas tecnologias, utilizando as MA's, diversificando estratégias e técnicas de ensino, no anseio de tonar o conteúdo mais atrativo, dinâmico e prazeroso.

\section{Referências}

Bacich, L., Tanzi Neto, A., \& Trevisani, F. de M. (2015). Ensino Híbrido: Personalização e tecnologia na educação. Penso.

Barreto, R. G. (2004). Tecnologia e Educação: Trabalho e Formação Docente, Educ. Soc., 25(89), 1181-1201, http://www.cedes.unicamp.br

Coletto, P. M. de C., Battini, O., Monteiro, E. (2018). Tecnologias da informação e comunicação e as metodologias ativas: Elementos para o trabalho docente no ensino superior. Revista Prática Docente. Instituto Federal de Mato Grosso. 3(2), 798-812.

Coutto, G. S. et al. (2020) Formação continuada e intervenções pedagógicas: ensino e aprendizagem na escola Estadual Ivone Borkwoski de Lima. Revista Prática Docente. Instituto Federal de Mato Grosso. 5(2). 1355-1373.

Christensen, C. M, Horn, M. B, \& Staker, H. (2013). Ensino Híbrido: uma Inovação Disruptiva? Uma introdução à teoria dos híbridos (2013). https://porvir.org/wp-content/uploads/2014/08/PT_Is-K-12-blended-learning-disruptive-Final.pdf

Dewey, J. (1959). Democracia e Educação: introdução à filosofia da educação. (3a ed.), Companhia Editora Nacional.

Freire, Paulo. (2009). Pedagogia da Autonomia. (36a ed.), Paz e Terra.

Freire, Paulo. (2014). Pedagogia do Oprimido. Paz e Terra.

Gaeta, C, Masetto, M. (2010). Metodologias Ativas e o Processo de Aprendizagem na Perspectiva da Inovação. PBL 2010 Congresso Internacional. http://each.uspnet.usp.br/pbl2010/trabs/trabalhos/TC0287-1.pdf

Gil, A. C. (2002). Como elaborar projetos de pesquisa. (4a ed.), Atlas.

Libâneo, J.C. (2013). Didática. Cortez.

Moran, J. (2015). Mudando a educação com metodologias ativas. [Coleção Mídias Contemporâneas. Convergências Midiáticas, Educação e Cidadania: aproximações jovens. Vol. II] Carlos Alberto de Souza e Ofelia Elisa Torres Morales (orgs.). PG: Foca Foto-PROEX/UEPG.

Moran, J. (2020). Metodologias ativas para uma aprendizagem mais profunda. http://www2.eca.usp.br/moran/wp-content/uploads/2013/12/metodolo gias_moran1.pdf

Peixoto, A. G. (2016). O uso de metodologias ativas como ferramenta de potencialização da aprendizagem de diagramas de caso de uso. Período Científico Outras Palavras, volume 12, número 2, p. 39.

Prestes, M. L. M. A pesquisa e a construção do conhecimento científico: do planejamento aos testos, da escola à academia. (4a ed.), Rêspel: 2013

Rother, E. T. (2020). Revisão Sistemática x Revisão Narrativa. https://www.scielo.br/pdf/ape/v20n2/a01v20n2.pdf 